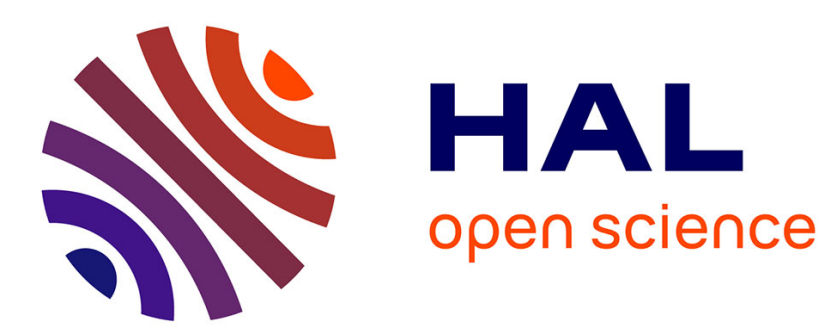

\title{
Observations of convective cooling in the tropical tropopause layer in AIRS data
}

\author{
H. Kim, A. E. Dessler
}

\section{To cite this version:}

H. Kim, A. E. Dessler. Observations of convective cooling in the tropical tropopause layer in AIRS data. Atmospheric Chemistry and Physics Discussions, 2004, 4 (6), pp.7615-7629. hal-00301509

\section{HAL Id: hal-00301509 \\ https://hal.science/hal-00301509}

Submitted on 19 Nov 2004

HAL is a multi-disciplinary open access archive for the deposit and dissemination of scientific research documents, whether they are published or not. The documents may come from teaching and research institutions in France or abroad, or from public or private research centers.
L'archive ouverte pluridisciplinaire HAL, est destinée au dépôt et à la diffusion de documents scientifiques de niveau recherche, publiés ou non, émanant des établissements d'enseignement et de recherche français ou étrangers, des laboratoires publics ou privés. 
Atmos. Chem. Phys. Discuss., 4, 7615-7629, 2004

www.atmos-chem-phys.org/acpd/4/7615/

SRef-ID: 1680-7375/acpd/2004-4-7615

European Geosciences Union
Atmospheric

Chemistry and Physics Discussions

\section{Observations of convective cooling in the tropical tropopause layer in AIRS data}

\section{H. Kim and A. E. Dessler}

Dept. of Meteorology and the Earth System Science Interdisciplinary Center, University of Maryland, College Park, MD 20742, USA

Received: 30 August 2004 - Accepted: 25 October 2004 - Published: 19 November 2004 Correspondence to: H. Kim (hyun@atmos.umd.edu)

(C) 2004 Author(s). This work is licensed under a Creative Commons License.

\section{ACPD}

$4,7615-7629,2004$

Observations of convective cooling in the tropical tropopause layer in AIRS data

H. Kim and A. E. Dessler

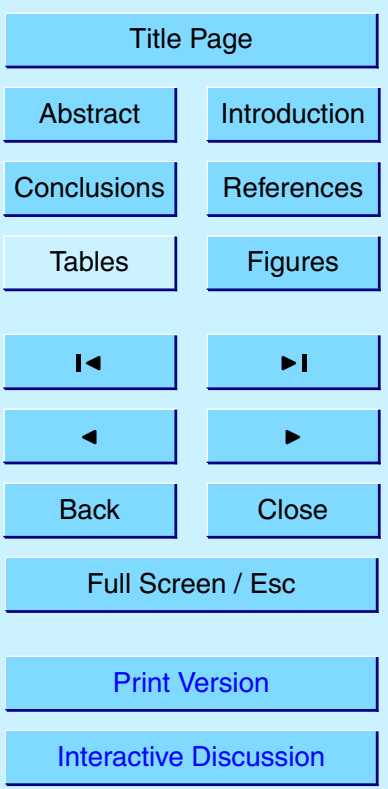




\section{Abstract}

We investigate the impact of convection on the thermal structure of the Tropical Tropopause Layer (TTL). We use temperature profiles measured by the Atmospheric Infrared Sounder (AIRS) onboard the Aqua satellite, and the time evolution of local 5 convection determined by the National Centers for Environmental Protection/Aviation Weather Center (NCEP/AWS) half-hourly infrared global geostationary composite. The observations demonstrate that the TTL is cooled by convection, in agreement with previous observations and model simulations. By using a global data set, we are able to investigate the variations in this convective cooling by season and region. The esti-

\section{biguously identify the cause of this cooling, our analysis suggests that radiative cooling} is likely not an explanation.

\section{Introduction}

Though it is well known that convection plays an important role in regulating the ther-

region between the tropical troposphere and stratosphere still remains unclear on the one hand, only a small fraction of convection extends to the vicinity of the tropical tropopause (Gettelman et al., 2002); on the other, there is no reason to suppose that infrequent events cannot still have an effect. The question how such infrequent deep convection affects this region's temperature is of great interest for many reasons, including the role this region's temperature plays in controlling lower stratospheric humidity (SPARC, 2000).

In this paper, we will study the effects of convection on the so-called tropical tropopause layer (TTL). We define the TTL to lie between the zero net radiative heating level (approximately $150 \mathrm{hPa}, 14 \mathrm{~km}, 355 \mathrm{~K}$ ) and the highest level that convection reaches $(70-80 \mathrm{hPa}, 18-19 \mathrm{~km}, 410-420 \mathrm{~K})$ (e.g., Sherwood and Dessler, 2000, 2001).

\section{Observations of convective cooling in the tropical tropopause layer in AIRS data}

H. Kim and A. E. Dessler

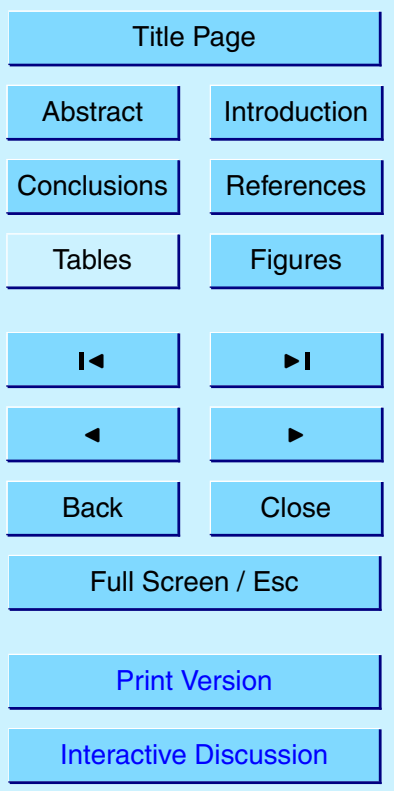


Various observational evidence suggests that tropopause temperatures are affected by convection. Using rawinsonde data during the International Winter Monsoon Experiment (Winter MONEX), Johnson and Kriete (1982) demonstrated that a significant cold anomaly occurs above the top of the mesoscale anvil clouds in the Indonesia re5 gion. Sherwood et al. (2003) used an 18-month set of radiosonde data from the tropical western Pacific region, and showed that active convective systems are locally associated with cold anomalies in the lower troposphere and near the tropopause. Using a dry baroclinic model with imposed idealized tropical convective heating, Highwood and Hoskins (1998) demonstrated that tropopause properties are directly related to 10 the large-scale convective heating occurring below. Randel et al. (2003) also showed that there is a strong correlation between cold temperature anomaly near the tropical tropopause and low outgoing long wave radiation data (a proxy for tropical deep convection) by analyzing data from Global Positioning System Meteorology (GPS/MET) observations. A cloud-resolving model by Kuang and Bretherton (2004) also showed 15 that convection has a cooling effect in the TTL.

Johnson and Kriete (1982) suggested adiabatic lifting, cloud-top radiative cooling, or turbulent mixing could explain the tropopause cooling. They also argued that the amount of very high and deep clouds may not be sufficient to cause appropriate cloudtop radiative cooling. Hartmann et al. (2001), however, showed that, if thin tropical tropopause cirrus $(\tau \ll 1)$ lies above convective anvils with tops above $13 \mathrm{~km}$, net radiative cooling from the cirrus could cause cooling. Adiabatic lifting induced by wave propagation also can contribute to cooling near the tropopause (Randel et al., 2003; Sherwood et al., 2003). Sherwood et al. (2003), however, argued that this cooling was induced by diabatic process and likely caused by the mixing of cold air that detrains from overshooting deep convection with its environment.

To study the response of the tropopause temperature to the convective events below, Sherwood et al. (2003) used a compositing technique that relates the temporal progression of tropical convective systems and the temperature changes in their vicinity. In this study, we extend the work of Sherwood et al. (2003) using a new, global
ACPD

4, 7615-7629, 2004

\section{Observations of convective cooling in the tropical tropopause layer in AIRS data}

H. Kim and A. E. Dessler

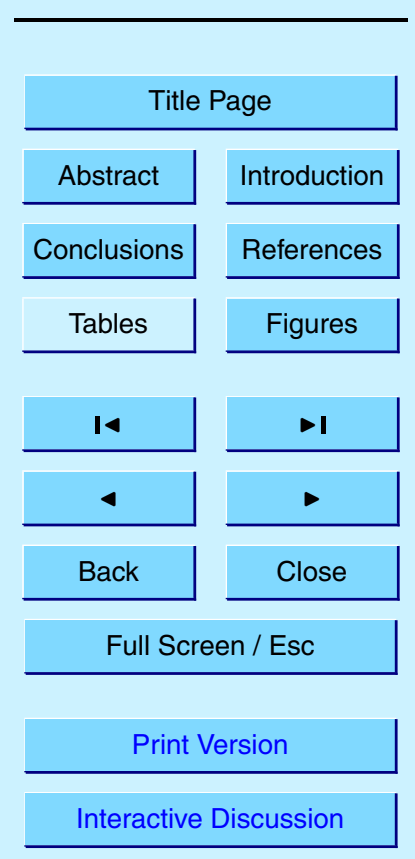


dataset. We will investigate the magnitude of the convective cooling as a function of location and season. We will also calculate cooling rates due to convection, which will help us narrow down the possible causes of the cooling.

\section{Data and methodology}

5 In order to observe the effects of convection on the temperature structure of the TTL, we need to take temperature measurements and sort them according to their "convective stage". We use temperature soundings measured by the Atmospheric Infrared Sounder (AIRS, onboard the "Aqua" spacecraft), obtained during February and July 2003 , between $30^{\circ} \mathrm{N}$ and $30^{\circ} \mathrm{S}$. AIRS level 2 products provide near-global temperature 10 soundings twice a day with $50-\mathrm{km}$ horizontal resolution, at an accuracy of $1^{\circ} \mathrm{C}$ in layers 1-km thick (Susskind et al., 1998). For the data we used in this study, version 3.0.8.0, retrievals are done only if the surface type is water, so our study is limited to areas over ocean.

We assign a "convective stage" to each AIRS temperature sounding using the Na15 tional Centers for Environmental Protection/Aviation Weather Center (NCEP/AWS) infrared global geostationary composite (hereafter the IR imagery), archived at the Global Hydrology Resource Center (GHRC). This infrared imagery dataset contains images of the brightness temperature $\left(T_{b}\right)$ converted from the $11-\mu \mathrm{m}$ infrared channels of four weather satellites in geosynchronous orbit, with 14-km horizontal resolution and half-hourly temporal resolution. These satellites are the Geostationary Meteorological Satellite (GMS, Japan), Geostationary Operational Environmental SatellitesEast (GOES-East), GOES-West (USA), and Meteosat (Europe), which cover the whole globe except a very narrow gap over the Indian Ocean (Kidder and Vonder Haar, 1995).

In order to determine what "convective stage" applies to a particular AIRS sounding, 25 we first determine the time history of convection in every $1^{\circ} \times 1^{\circ}$ box. We define convection as "occurring" during a 30 -min period if the fraction of pixels in a box with brightness temperatures below $208 \mathrm{~K}\left(\mathrm{C}_{208}\right)$ is greater than $10 \%$ (this is the same threshold
ACPD

$4,7615-7629,2004$

\section{Observations of convective cooling in the tropical \\ tropopause layer in AIRS data}

H. Kim and A. E. Dessler

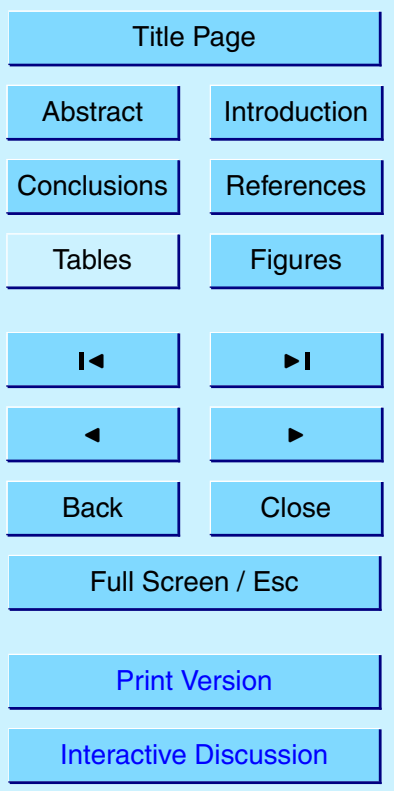


as used by Sherwood and Wahrlich, 1999); it is not occurring if $\mathrm{C}_{208}<10 \%$. Using this method, we determine when convection starts and stops for each $1^{\circ} \times 1^{\circ}$ box.

For each AIRS temperature profile, we look within $\pm 3 \mathrm{~h}$ of the profiles' measurement time and determine the time history of convection in the $1^{\circ} \times 1^{\circ}$ box around the 5 measurement.

Stage 0: No convection within $\pm 3 \mathrm{~h}$

Stage 1: No convection in the previous $3 \mathrm{~h}$, convection starts in the next $3 \mathrm{~h}$

Stage 2: Convection started in the previous $3 \mathrm{~h}$ and continues for the next $3 \mathrm{~h}$

Stage 3: On-going $\mathrm{C}_{208}>10 \%$ for the entire 6 -h period

15

Stage 4: Convection on-going during previous $3 \mathrm{~h}$, convection stops in the next $3 \mathrm{~h}$

Stage 5: Convection stopped in the previous $3 \mathrm{~h}$, no convection in the next $3 \mathrm{~h}$

It should be noted that we did not consider advection of clouds. Therefore, we are not 20 able to distinguish a system moving in from one that grows locally. We also throw out any measurement whose convective history does not fall into one of those categories. For example, convection that lasts less than $6 \mathrm{~h}$ does not fall into any category and therefore is not analyzed here.

\section{Results and discussion}

25 Figures $1 \mathrm{a}$ and $\mathrm{b}$ show mean temperature anomalies (the difference between the measured profile and the average of all measurements in that $1^{\circ} \times 1^{\circ}$ box over the entire month) during the convective stages in February 2003 and in July 2003. Horizon-
ACPD

4, 7615-7629, 2004

Observations of convective cooling in the tropical tropopause layer in AIRS data

H. Kim and A. E. Dessler

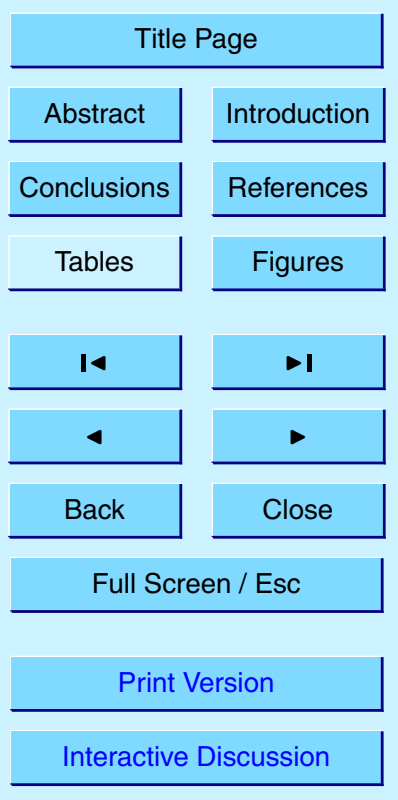


tal bars show the $95 \%$ confidence interval for the mean of the temperature anomaly. In agreement with expectations, the anomalies during stage one are small because convection has not yet fully started in this stage. Only small numbers of convective events are intense enough, generating small anomalies in the temperature profile. The 5 anomalies grow progressively larger in stages two and three, as convection goes on progressively longer. In stage four, the anomalies decrease as convection becomes weaker and begins to dissipate. For stage five, after convection has terminated, the anomalies rapidly decrease to near zero. We also performed diurnal separation: the over-plotted dotted line is from nighttime data only. AIRS measures the temperature 10 profile twice a day, around 01:30 a.m. and 01:30 p.m. in local time. There is no significant diurnal cycle in the anomalies.

We see that convection warms the troposphere up to an altitude of around $120 \mathrm{hPa}$, with cooling in the TTL between 120 and $70 \mathrm{hPa}$. The magnitude of the warming anomalies generally agrees well with previous studies. Sherwood and Wahrlich (1999) showed warming of up to $1.3 \mathrm{~K}$, peaking around $300 \mathrm{hPa}$, during convection, using rawinsonde data from the Western Pacific area. Bhat et al. (2002) also demonstrated that, during the convective period, the atmosphere became warmer between $6 \mathrm{~km}$ and $13 \mathrm{~km}$ height, and the amount of warming was less than $1.5 \mathrm{~K}$ relative to the mean temperature profile of the observation period.

20 Cold temperature anomalies at the tropopause level have also been seen previously in both observations (Johnson and Kriete, 1982; Sherwood et al., 2003) and in a model study (Kuang and Bretherton, 2004). The amount of cooling in stage 3 is larger in February $(\sim-2.15 \mathrm{~K})$ compared to that of July $(\sim-1.87 \mathrm{~K})$. Our result is larger than that of Sherwood et al. (2003), who found $\sim 1-\mathrm{K}$ cooling just below the tropopause. Johnson and Kriete (1982) reported a rather large value, $-6 \mathrm{~K} \sim-10 \mathrm{~K}$, studying three wintertime convective events near Indonesia. We believe that this magnitude difference comes from the difference of sampling numbers, region and period. Kuang and Bretherton's (2004) model study also showed that a maximum of $\sim 10-\mathrm{K}$ cooling may be attributed to convective cooling at the cold point tropopause. In addition, we per-

ACPD

4, 7615-7629, 2004

\section{Observations of convective cooling in the tropical tropopause layer in AIRS data}

H. Kim and A. E. Dessler

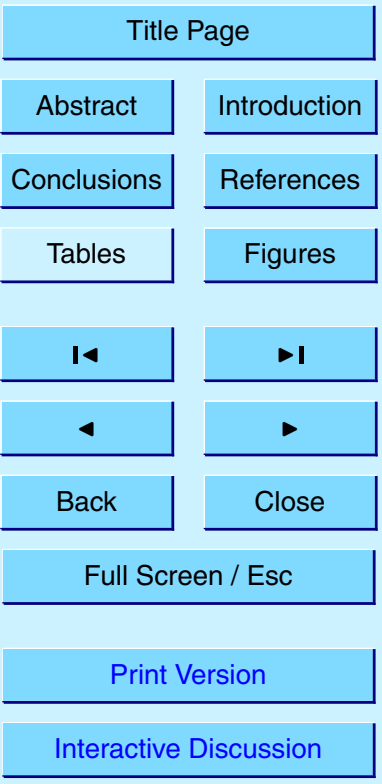


formed the same analysis with data over continents (not shown), which is invalidated by the data quality assurance flag in the current version of retrieval, and found a similar temperature anomaly pattern to that over ocean. The only discrepancy was a larger anomaly near the surface, showing the effect of the small heat capacity of land.

5 Another quantity of interest is the tropopause cooling rate due to convection. To obtain this, we plot the elapsed time since convection started against 100-hPa potential temperature anomaly (temperature anomalies at a pressure level $\mathrm{P}$ are converted to potential temperature anomalies by multiplying by $\left(\mathrm{P} / \mathrm{P}_{o}\right)^{-2 / 7}$, where $\mathrm{P}_{o}$ is $\left.1000-\mathrm{hPa}\right)$. The potential temperature anomalies as a function of time since the start of convection are shown in Fig. 2. Symbols indicate convective stages. A least-squares fit to the data is shown as a dotted line, and its slope is the cooling rate. The estimated cooling rate (in potential temperature units) at the tropopause from this line-fit is $-7.5 \mathrm{~K} /$ day for February 2003 , and is $-9.1 \mathrm{~K} /$ day for July 2003 . This cooling rate agrees well with the estimate by Sherwood et al. (2003), $-5 \sim-10 \mathrm{~K} /$ day, but is larger than the result of 15 Kuang and Bretherton (2004), which showed a few tenths of a K/day.

There are two arbitrary thresholds used in this analysis: $208 \mathrm{~K}$, which is the threshold $\mathrm{T}_{b}$ representing "deep convection", and $10 \%$, which is the fraction of pixels with brightness temperature less than $\mathrm{T}_{b}$ required before a region is considered to be "convective". Figure 3 shows how our results change when these two thresholds are adjusted. 20 Figure 3a shows the average 100-hPa anomaly during stages 2 through 4 as a function of fractional coverage of deep convection. The different symbols in the figure show the results for different values of $T_{b}$. As one might expect, using either a lower value of $T_{b}$ or a higher required fraction of convective pixels results in larger (more negative) temperature anomalies. This makes sense because both of these represent more vigorous convection, which should also be associated with stronger cooling. The results are almost insensitive to $T_{b}$ threshold until the fractional threshold is over $50 \%$. If we take a higher fractional threshold, over $50 \%$, the number of available cases decreases rapidly, and results are mostly scattered. This sensitivity test is consistent with Sherwood and Wahrlich (1999), who also showed that results were not sensitive to the lower fractional
ACPD

$4,7615-7629,2004$

\section{Observations of convective cooling in the tropical \\ tropopause layer in AIRS data}

H. Kim and A. E. Dessler

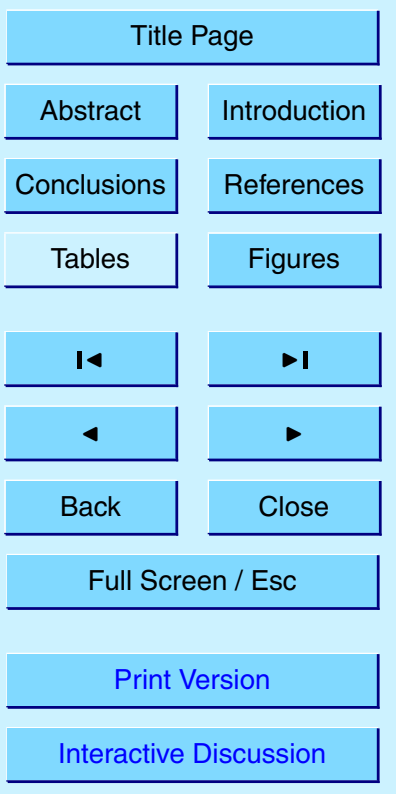


threshold. The sensitivity of the cooling rate to these assumed thresholds is also not significant, with values between 5 and $10 \mathrm{~K} /$ day for the low fractional threshold range. This can be seen in Fig. 3b. We also performed the same sensitivity test by changing the box size to $2^{\circ} \times 2^{\circ}$, and we could not find any significant difference.

$5 \quad$ There are several previously identified mechanisms that can explain this convective cooling. This includes forced mesoscale ascent near the tropopause, which would lead to adiabatic cooling (Johnson and Kriete, 1982; Fritsch and Brown, 1982). Using a simple wave propagation model, Sherwood et al. (2003) demonstrated that the cold anomaly below $100-\mathrm{hPa}$ could be partly accounted for by adiabatic lofting associated 10 with wave propagation by heating in the troposphere, though the cold anomaly was able to extend to the tropopause level only in strong heating cases. Sherwood et al. (2003) also argued that there was a diabatic component to the motion. They deduced this by assuming that the "cold point" of a profile was a material surface, and observing that it moves downward, toward higher pressures and colder potential temperatures, in 15 response to convection, showing that the cold point's potential temperature decreased during convection. Our data does not have sufficient vertical resolution to verify or contradict this conclusion.

If the cooling is diabatic, there are several possible explanations. Radiative cooling from high and optically thick clouds is one. However, Fig. 1 shows that the nighttimeonly convective cooling agrees closely with the 24-h average convective cooling. Since absorption of solar radiation makes an important contribution to cloud top radiative heating during the day, we would expect day-night differences between the daytime and nighttime convective cooling if clouds were responsible. We do not see that, suggesting that cloud-top cooling from thick clouds is not the explanation.

The other explanation for diabatic tropopause cooling is the turbulent mixing of overshooting air with its environment (Sherwood, 2000). Undilute convection that rises above its level of neutral buoyancy (LNB) (i.e., is "overshooting"), will be colder than its environment. If this air subsequently mixes into the environment, it will cause cooling. A simple calculation demonstrates the potential of this process for cooling the TTL. If
ACPD

4, 7615-7629, 2004

\section{Observations of convective cooling in the tropical tropopause layer in AIRS data}

H. Kim and A. E. Dessler

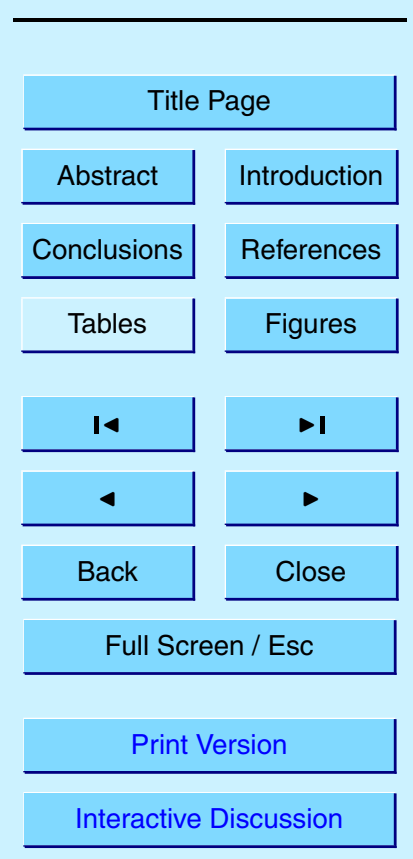


we assume mixing between air that ascended adiabatically to $100 \mathrm{hPa}$ (with potential temperature $\theta_{a}$ ) and the environment (potential temperature $\theta$ ), we can estimate how much overshooting air is needed to generate the cooling rate measured in Fig. 2 . If mixing occurs, the temperature of the mixture will be determined by the ratio of the 5 amount of overshooting air to the amount of environmental air. Assuming the fraction of detraining air in the mixture is $\Delta r$, the potential temperature difference between the mixture and the environment is

$\Delta \theta=\left(\frac{\Delta \mathrm{r}}{\Delta \mathrm{r}+1} \theta_{\mathrm{a}}+\frac{1}{\Delta \mathrm{r}+1} \theta\right)-\theta$.

If we rearrange this equation for $\Delta \mathrm{r}$,

10

$\Delta \mathrm{r}=\frac{\Delta \theta}{\left(\theta_{\mathrm{a}}-\theta\right)-\Delta \theta}=\frac{\mathrm{Q} \cdot \Delta \mathrm{t}}{\left(\theta_{\mathrm{a}}-\theta\right)-\mathrm{Q} \cdot \Delta \mathrm{t}}$,

where $Q$ is the cooling rate, which we measured to be about $-7.5 \mathrm{~K} /$ day.

For the usual time scale of convection $(\Delta \mathrm{t} \sim 10 \mathrm{~h})$ and usual values of potential temperatures $\left(\theta_{a}=355 \mathrm{~K}\right.$ at LNB and $\theta=375 \mathrm{~K}$ at $\left.100 \mathrm{hPa}\right)$, the fraction of detraining air in the mixture that is needed to genetrate the $-7.5 \mathrm{~K} /$ day cooling is $\sim 19 \%$, which implies 15 ap approximately $44 \%$ of tropopause air should be replaced by overshooting convectin in a day to satisfy the observed cooling rate. This is a difficult number to verify, but there are some estimates we can use. First of all, it should be noted that this turnover timescale is obtained only over a single convective event, not over the whole tropics. In our study, $3 \%$ of the total AIRS profiles were classified as 'convective' (stages 2 through 4 ), therefore, if we assume that all vertical mass transport from the LNB to 100-hPa level occurs during these convections, the required fraction of air transported by overshooting to satisfy the observed cooling rate is $1.32 \% /$ day $(=44 \% /$ day $\times 3 \%)$, in the tropical average. Dessler (2002) found a turnover time of 2 months near the tropopause, by analyzing ER-2 measurements of $\mathrm{O}_{3}$ and $\mathrm{CO}$, which corresponds to the $1.7 \%$ /day mass flux. It looks reasonable that this amount is enough to cause the convective cooling rate we observed in this study. Furthermore, in this calculation, we assumed the measured
ACPD

$4,7615-7629,2004$

\section{Observations of convective cooling in the tropical tropopause layer in AIRS data}

H. Kim and A. E. Dessler

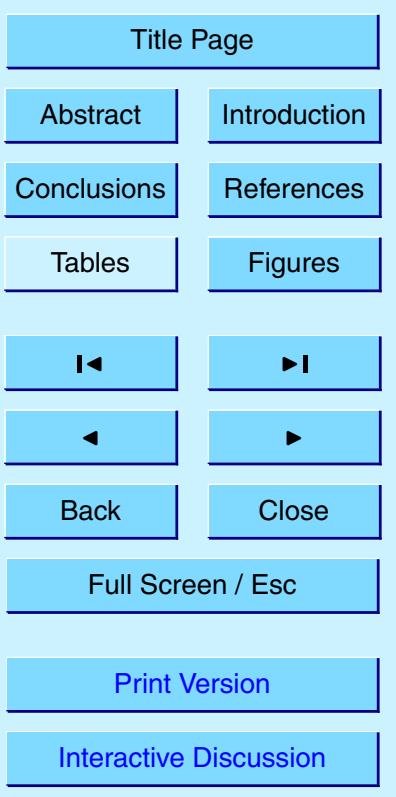


cooling is totally induced by turbulent mixing. If other processes, mentioned above, can partly contribute to the measured cooling, the required overshooting amount will be lower, showing the turbulent mixing still has enough potential to cause convective cooling near the tropopause.

\section{4. Conclusions}

In this paper, we have investigated the effects of convection on the temperature structure of the TTL in February 2003 and July 2003 using a global data set. Our analysis indicates that a significant cold anomaly occurs in the TTL in response to convection, in both day and night and during two times of year. We estimate cooling rates of around $10-7.5 \mathrm{~K} /$ day in February 2003 and $-9 \mathrm{~K} /$ day in July 2003 (potential temperature units) at $100 \mathrm{hPa}$ during convection. While we cannot unambiguously assign a cause to this cooling, we do not believe it arises from radiation from either thick or thin clouds.

We do show that mixing in of cold air from overshooting convection is a potentially reasonable explanation for the cooling. This air detraining from overshooting deep convection is not only cold but also might be very dry, so might also play an important role in determining humidity in the TTL and in the lower stratosphere.

Acknowledgements. We gratefully acknowledge support from a NASA EOS/IDS grant to the University of Maryland. We'd also like to thank the AIRS science team for the production of their data sets and the GSFC DAAC and the GHRC for distributing the data.

\section{References}

Bhat, G. S., Chakraborty, A., Nanjundiah, R. S., and Srinivasan, J.: Vertical thermal structure of the atmosphere during active and weak phases of convection over the north Bay of Bengal: Observation and model results, Curr. Sci. India., 83 (3), 296-302, 2002.

Dessler, A. E.: The effect of deep, tropical convection on the tropical tropopause layer, J.
ACPD

4, 7615-7629, 2004

Observations of convective cooling in the tropical

tropopause layer in AIRS data

H. Kim and A. E. Dessler

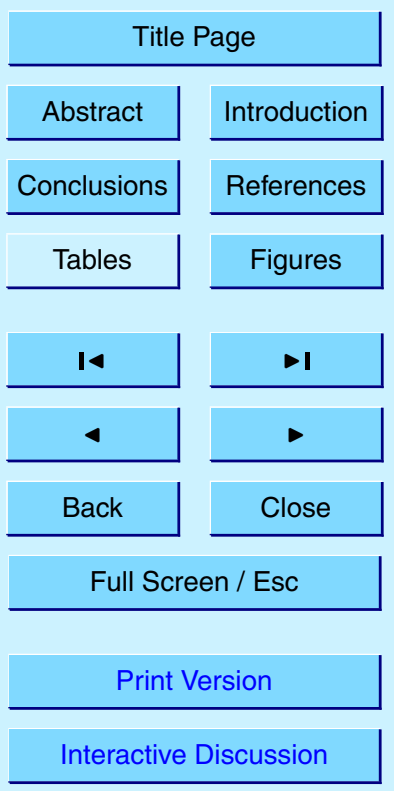


Fritsch, J. M. and Brown, J. M.: On the generation of convectively driven mesohighs aloft, Mon. Wea. Rev., 110, 1554-1563, 1982.

Gettelman, A., Salby, M. L., and Sassi, F.: The distribution and influence of convection in the tropical tropopause region, J. Geophys. Res., 107 (D10), doi:10.1029/2001JD001048, 52002.

Hartmann, D. L., Holton, J. R., and Fu, Q.: The heat balance of the tropical tropopause, cirrus, and stratospheric dehydration, Geophys. Res. Lett., 28 (10), 1969-1972, 2001.

Highwood, E. J. and Hoskins, B. J.: The tropical tropopause, Quart. J. R. Met. Soc., 124, 1579-1604, 1998.

10 Johnson, R. H. and Kriete, D. C.: Thermodynamic and Circulation Characteristics of Winter Monsoon Tropical Mesoscale Convection, Mon. Wea. Rev., 110 (12), 1898-1911, 1982.

Kidder, S. Q. and Vonder Haar, T. H.: Satellite Meteorology, Academic Press Inc., 1995.

Kuang, Z. and Bretherton, C. S.: Convective influence on the heat balance of the tropical tropopause layer: A cloud-resolving model study, J. Atmos. Sci., accepted, 2004.

15 Randel, W. J., Wu, F., and Rivera Ríos, W.: Thermal variability of the tropical tropopause region derived from GPS/MET observations, J. Geophys. Res., 108 (D1), 4024, doi:10.1029/2002JD002595, 2003.

Sherwood, S. C.: A stratospheric "drain" over the maritime continent, Geophys. Res. Lett., 27 (5), 677-680, 2000.

20 Sherwood, S. C. and Dessler, A. E.: On the control of stratospheric humidity, Geophys. Res. Lett., 27 (16), 2513-2516, 2000.

Sherwood, S. C. and Dessler, A. E.: A model for transport across the tropical tropopause, J. Atmos. Sci., 7, 765-779, 2001.

Sherwood, S. C. and Warhlich, R.: Observed evolution of tropical deep convective events and their environment, Mon. Wea. Rev., 127 (8), 1777-1795, 1999.

Sherwood, S. C., Horinouchi, T., and Zeleznik, H. A.: Convective impact on temperatures observed near the tropical tropopause, J. Atmos. Sci., 60 (15), 1847-1856, 2003.

SPARC: Kley, D., Russell III, J. M., and Phillips, C.: SPARC Report on Distribution and Variability of Water Vapour in the Upper Troposphere and Lower Stratosphere, in SPARC Assessment of Upper Tropospheric and Stratospheric Water Vapour (WMO/TD-No. 1043), WCRP-113, 2000.

Susskind, J., Barnet, C., and Blaisdell, J.: Determination of atmospheric and surface parameters from simulated AIRS/AMSU/HSB sounding data: Retrieval and cloud clearing method-

ACPD

4, 7615-7629, 2004

Observations of

convective cooling in the tropical

tropopause layer in AIRS data

H. Kim and A. E. Dessler

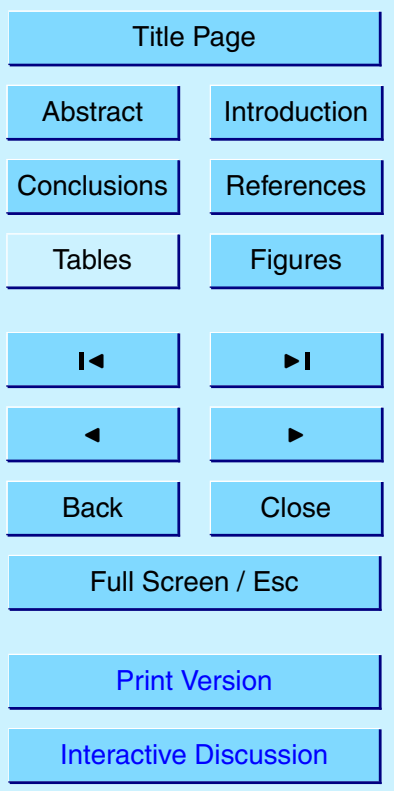


ology, Adv. Space Res., 21 (3), 369-384, 1998.

\section{ACPD}

4, 7615-7629, 2004

\section{Observations of} convective cooling in the tropical tropopause layer in AIRS data

H. Kim and A. E. Dessler

Title Page

\begin{tabular}{c|c} 
Abstract & Introduction \\
\cline { 1 - 1 } Conclusions & References \\
\cline { 1 - 2 } Tables & Figures \\
\hline
\end{tabular}

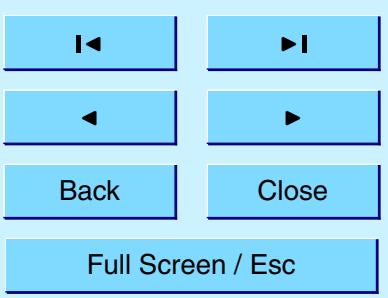

Print Version

Interactive Discussion 


\section{ACPD}

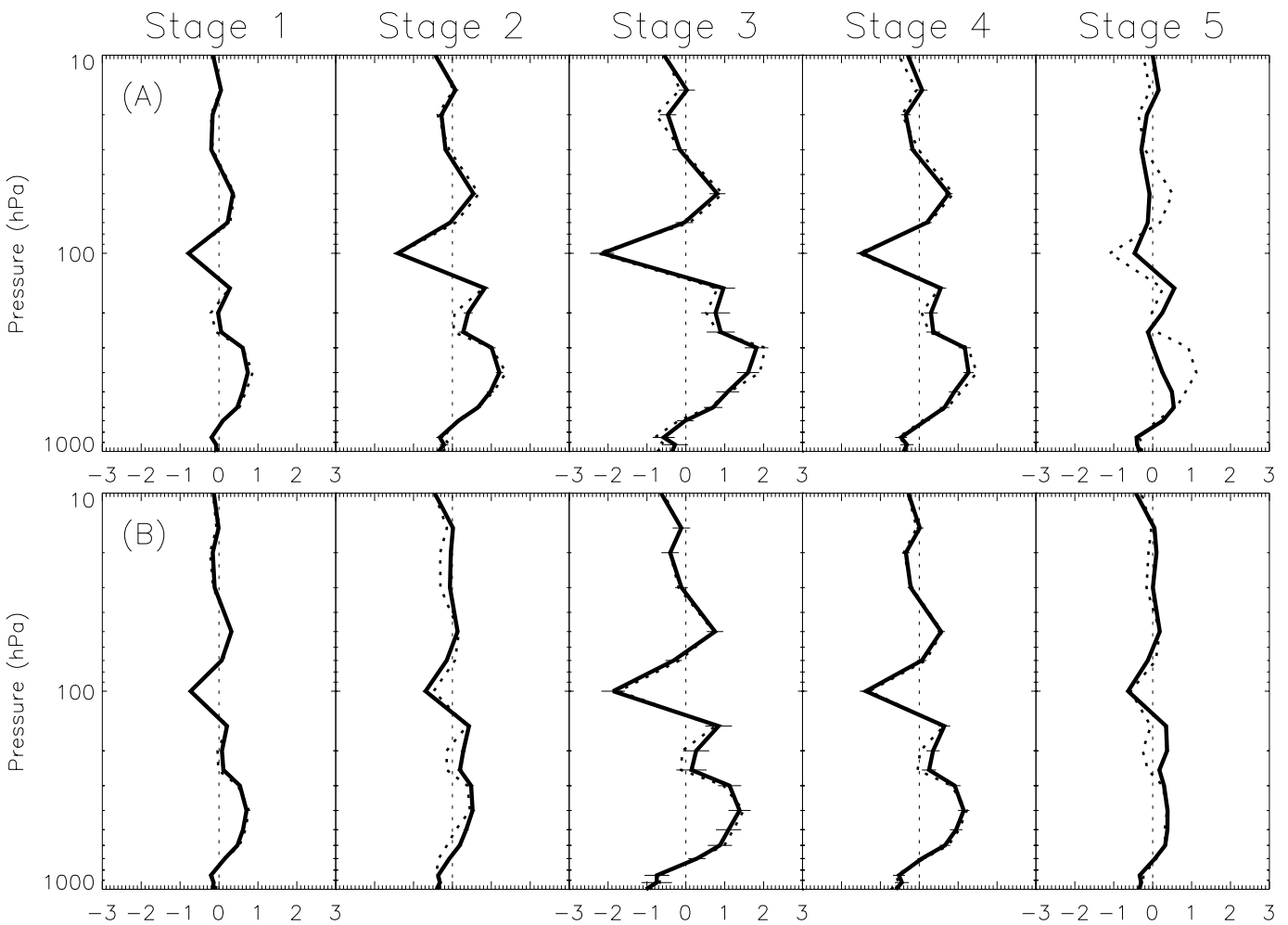

Fig. 1. Mean temperature anomaly over convective stages for (a) February 2003 and (b) July 2003. Dotted lines indicate values from nighttime only. Horizontal bars at each pressure level mean the $95 \%$ confidence interval for mean of the temperature anomaly.
$4,7615-7629,2004$

\section{Observations of} convective cooling in the tropical tropopause layer in AIRS data

H. Kim and A. E. Dessler

Title Page

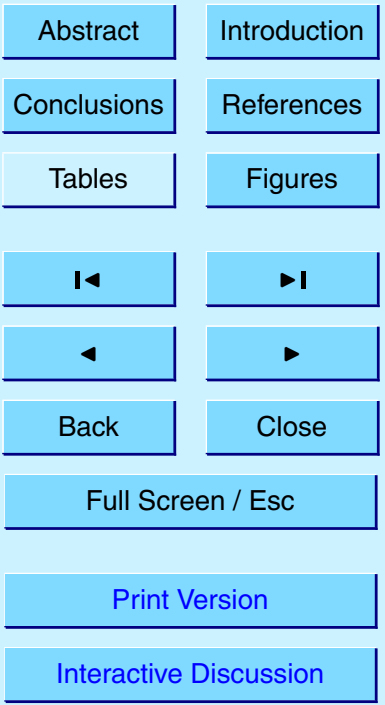




\section{ACPD}
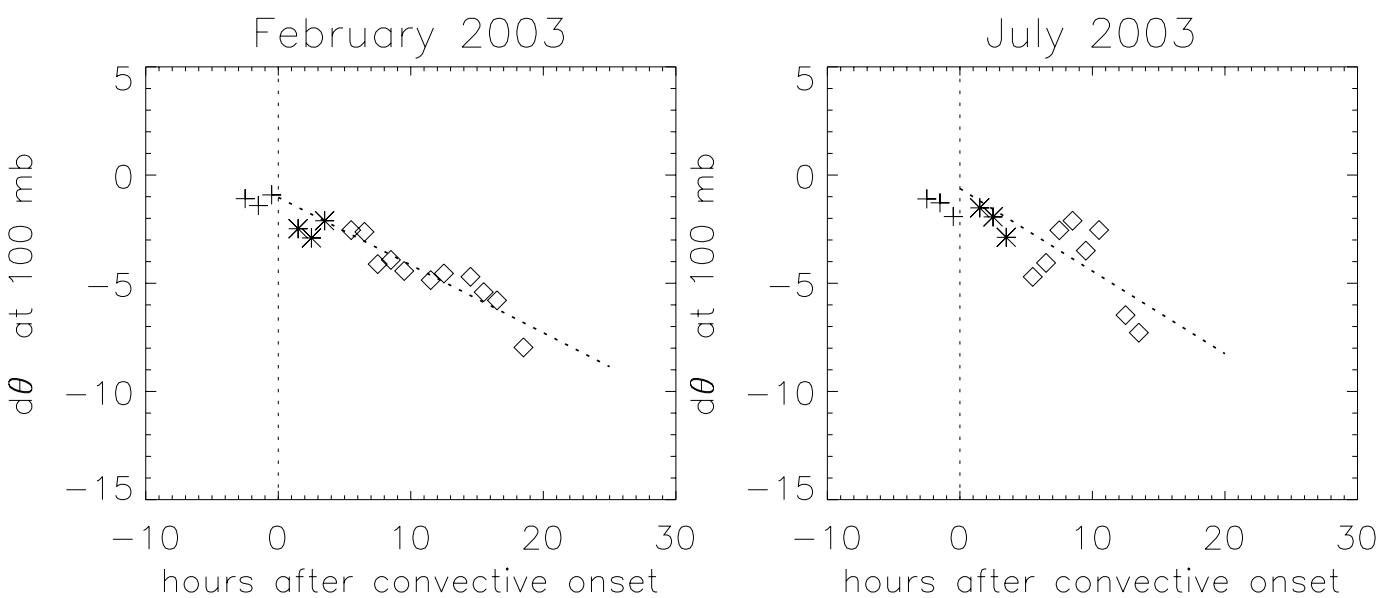

Fig. 2. Cooling rate calculation for February 2003 and for July 2003. Shown symbols are the potential temperature anomaly at $100 \mathrm{hPa}$ averaged in 1 - $\mathrm{h}$ bin of time after convection starts. Symbols,$+{ }^{*}$ and $\diamond$ represent stage 1,2 , and 3 . Estimated cooling rates are $-7.5 \mathrm{~K} /$ day in February 2003 and $-9.1 \mathrm{~K} /$ day in July 2003.

4, 7615-7629, 2004

\section{Observations of convective cooling in the tropical tropopause layer in AIRS data}

H. Kim and A. E. Dessler

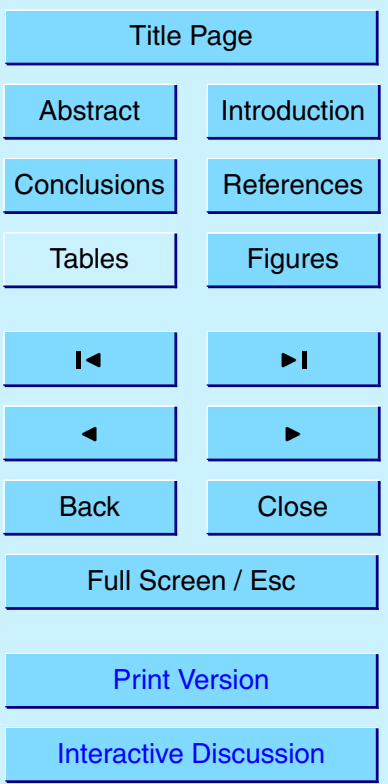




\section{ACPD}

$204 K(+) 206 K(*) 208 K(\diamond) 210 K(\square) 212 K(\Delta)$

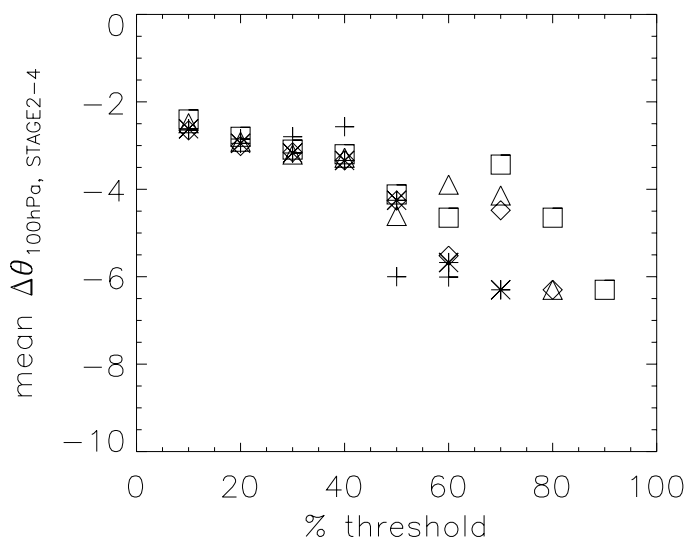

4, 7615-7629, 2004

Observations of convective cooling in the tropical

tropopause layer in AIRS data

H. Kim and A. E. Dessler

Title Page

\begin{tabular}{c|c|} 
Abstract & Introduction \\
\cline { 1 - 1 } Conclusions & References \\
\hline Tables & Figures \\
\hline
\end{tabular}

Fig. 3. Sensitivity tests in (a) mean potential temperature anomalies at $100 \mathrm{hPa}$ during convective event (stage 2-4), and (b) estimated cooling rates. Symbols indicate different "deep convection" thresholds. Changes in $\mathrm{T}_{b}$ threshold are shown as different symbols (Symbols + , $*, \diamond, \square$, and $\Delta$ indicate $\mathrm{T}_{b}$ threshold $204 \mathrm{~K}, 206 \mathrm{~K}, 208 \mathrm{~K}, 210 \mathrm{~K}$, and $212 \mathrm{~K}$, respectively), and the changes of fractional threshold are shown in $\mathrm{x}$-axis.

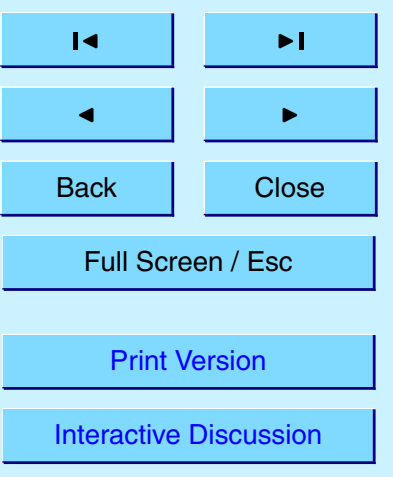

